\title{
The association between fever and pyuria in children older than one month
}

\author{
Saeed Mohajeri ${ }^{\circledR}$, Pouria Hemmati ${ }^{*}$, Morteza Sedehi ${ }^{\circledR}$ \\ Department of Pediatrics, Faculty of Medicine,Shahrekord University of Medical Sciences, Shahrekord, Iran
}

\section{A R T I C L E I N F O}

Article Type:

Original

\section{Article History:}

Received: 26 January 2019

Accepted: 4 May 2019

Published online: 8 June 2019

\section{Keywords:}

Pyuria,

Interstitial nephritis

Fever

\begin{abstract}
A B S T R A C T
Introduction: Some assumptions have been made on the probable association between fever and pyuria.

Objectives: The present study aimed to investigate the association between fever and pyuria. Patients and Methods: In this case-control study, 90 febrile and 90 non-febrile children aged more than one month who were admitted to the pediatric ward were included. Urine specimens of children less than 2 years of age were collected by urine bag. Midstream urine samples were collected and immediately sent to the laboratory for complete urinalysis and urine culture.

Results: Overall, $6.7 \%$ in febrile children and $2.2 \%$ in control group had pyuria however there was no significant association between fever and pyuria $(P>0.05)$. Additionally, no association between the presence of pyuria and type of disease was detected $(P>0.40)$.

Conclusion: The present study could not reveal any association between fever and pyuria in children older than one month.
\end{abstract}

Implication for health policy/practice/research/medical education:

In this cross-sectional study, 90 febrile and 90 non-febrile children aged more than one month, we found no association between fever and pyuria in children older than one month.

Please cite this paper as: Mohajeri S, Hemmati P, Sedehi M. The association between fever and pyuria in children older than one month. J Renal Inj Prev. 2019; 8(3): 240-242. DOI: 10.15171/jrip.2019.45.

\section{Introduction}

Overally, fever is the most common patient's chief complaint as the reason for visiting a pediatrician or family physician. Fever in children is generally defined temperature higher than $38^{\circ} \mathrm{C}$ using rectal thermometer and temperature higher than $37.8^{\circ} \mathrm{C}$ using oral termometer or temperature higher than $37.2^{\circ} \mathrm{C}$ using axillary termometer $(1,2)$. The most common cause of fever in children is infections. Common viruses and bacterial diseases are the most source of fever in children (1). Fever can be also caused by tissue damages due to burns, malignancies, medications such as amphotericin B, inflammatory diseases, or even metabolic disorders (2). Urinalysis testing is one of the first evaluations that is performed for the suspected children. A urine analysis that shows pyuria suggests an infection, however sterile pyuria may also be associated with urethritis, vaginitis, kidney stones, glomerulonephritis, and interstitial nephritis (4). Pyuria in children is referred to WBC more than five in any high-power field (HPF) microscopy (3). Pyuria without bacteriuria is called sterile pyuria. WBC excretion in urine is a indicator for inflammatory or infectious urinary tract disorder. Systemic inflammatory diseases such as Kawasaki are also identified as other causes for pyuria (4). Structural and anatomical abnormalities of the genitourinary tract can also cause sterile pyuria. In particular, attention should be paid to hydronephrosis, polycyclic kidney, vesicoureteral reflux or nephrocalcinosis. Pathologic kidney diseases such as papillary necrosis, sickle cell nephropathy and diabetic nephropathy are other causes of pyuria. In addition, tubulointerstitial disorders such as interstitial nephritis, lupus nephritis, and kidney transplantation may also lead to pyuria.

\section{Objectives}

This study was conducted to investigate the association between fever and pyuria in children for better controlling of fever and pyuria as the common findings in children.

Patients and Methods

Study design

In this case-control study, 90 febrile cases aged more than 
one month who were admitted to the pediatric ward of Hajar hospital in Shahrekord without causative reasons for pyuria were included. Additionally, 90 children with the same range of age who were hospitalized without fever and other underlying causes for pyuria were selected as the control. Patients in two groups were matched for age and gender. All patients were physically examined and then, the urine specimen was taken and immediately sent to the laboratory for complete urine testing and culture. After urine sample collection, those with normal urine test continued the project, but those children with the evidence of pyuria were assessed regarding to, urine culture, determining blood urea nitrogen (BUN)/creatinine (Cr) and urinary system sonography. Each patient with pyuria was also examined by nephrologist to ensure that other causes of pyuria were be excluded. If necessary, additional tests were carried out too. In children with at least one of the causative factors, for pyuria the case was excluded from the study.

\section{Ethical issues}

The research followed the tenets of the Declaration of Helsinki. Written informed consent was obtained from parents of participants. The research was approved by the ethical committee of Shahrekord University of Medical Sciences (\# IR.SKUMS.REC.1395.292). This manuscript is adapted from a doctoral dissertation in medicine (\#registration code 1215) by Pouria Hemmati.

\section{Statistical analysis}

For statistical analysis, results were presented as mean \pm standard deviation (SD) for quantitative variables and were summarized by absolute frequencies and percentages for categorical variables. Normality of data was analyzed using the Kolmogorov-Smirnov test. Quantitative variables were also compared with L test or Mann Whitney U test. For the statistical analysis, the statistical software SPSS version 16.0 for Windows (SPSS Inc., Chicago, IL) was used. $P$ values of 0.05 or less were considered statistically significant.

\section{Results}

In this study, 64 cases with pyuria were excluded due to the presence of other underlying causes for pyuria including positive urine culture (40.6\%), dehydration (14.0\%), kidney disorders (6.25\%), renal stone (9.3\%), or vesicourethral reflux (15.6\%). The mean body temperature in febrile and non-febrile groups was $38.69 \pm 0.05^{\circ} \mathrm{C}$ and
$37.09 \pm 0.03^{\circ} \mathrm{C}$ respectively $(P<0.001)$. The mean WBC count was also $4.03 / \mathrm{HPF}$ in febrile children and $2.12 / \mathrm{HPF}$ in control group with no significant difference $(P>0.05)$. Overall, $6.7 \%$ in febrile children and $2.2 \%$ in control group had pyuria without statistically meaningful difference $(P>0.05)$. However, no association between the presence of pyuria and type of the disease was detected $(P>0.40)$ (Table 1).

\section{Discussion}

As the first result, pyuria was revealed in $6.7 \%$ of children with fever and $2.2 \%$ in non-febrile group without significant difference. In a study by Turner and Coulthard, moderate pyuria was found in $43.0 \%$ of patients with fever and only in $6.0 \%$ of those without fever. While severe pyuria was revealed in $9 \%$ febrile children group and $0 \%$ in control group that was significantly difference. This difference in the results within the studies of Turner and Coulthard could be due to the difference in the criterion of defining pyuria (pyuria was defined over $10 \times 10^{6}$ leukocyte/L) (6). In a study by Hooker et al, $28 \%$ of febrile patients and $30.7 \%$ of non-febrile patients had pyuria without difference among them, which is comparable to our study (5). Similarly, in the study by Oikonomou et al (8), pyuria had no significant difference in febrile and non-febrile patients which is in accordance with the results of our study.

In the study of Sharif et al (7), the correlation between urinary leukocyte count and fever in patients with urinary tract infection was very weak.

In this study, the mean number of WBCs in urine was also measured by different diseases. But the count of WBCs did not show any meaningful association with the type of disease.

\section{Conclusion}

In this study, pyuria was compared in two children groups with and without fever. The mean body temperature in the febrile group was $38.69^{\circ} \mathrm{C}$ and in the non-febrile group was $37.09^{\circ} \mathrm{C}$. We found, no significant relationship between fever and pyuria. In the febrile group, the mean number of WBCs in the urine was higher $(4.03 / \mathrm{HPF})$ than the non-febrile group, (2.12/HPF), however no significant relationship between fever and WBC count in urine was detected.

Limitations of the study

Correct collection of urine specimen was potential

Table 1. Comparing body temperature and WBC count in the groups with and without fever

\begin{tabular}{llll}
\hline Item & Febrile group $(\mathbf{n}=90)$ & Non-febrile group $(\mathbf{n}=90)$ & $P$ value \\
\hline Temperature & $38.69 \pm 0.05$ & $37.09 \pm 0.03$ & $<0.001$ \\
WBCs count & $4.03 \pm 1.26$ & $2.12 \pm 0.34$ & 0.140 \\
Pyuria & $6(6.7 \%)$ & $2(2.2 \%)$ & 0.131 \\
\hline
\end{tabular}


limitation of this study.

\section{Acknowledgments}

This manuscript is adapted from a doctoral dissertation in medicine with registration code 1215 registered by Shahrekord University of Medical Sciences. We are extremely grateful to the management and staffs of the pediatric department at Hajar hospital who helped us with this study.

Authors' contribution

Study design; SM, Data Collection; PH, Data Analysis: MS, Manuscript writing: $\mathrm{HH}$.

\section{Conflicts of interest}

The author declared no competing interests.

\section{Ethical considerations}

Ethical issues (including plagiarism, data fabrication, double publication) have been completely observed by the authors.

\section{Funding/Support}

This Study supported by Shahrekord University of Medical Sciences, Shahrekord, Iran.

\section{References}

1. Ward M, Edwards M, Torchia M. Fever in children (beyond the basics). Washington: UpToDate; 2013 [cited 2015 June 15]. Available from: http://www.uptodate.com/ UPT/ 2017061/htm/.

2. Powell K, Stormorke A, Green M, Barret F. Infectious Diseases. In: Behrman R, Kliegmaer R, Jenson H, eds.
Nelson Textbook of Pediatrics. 17th ed. Philadelphia: Saunders; 2004. p. 839-61.

3. Vijayakumar M. Urinary tract infection and pyeionephritis. In: Vijayakumar M, ed. A Text Book Infectious Disease. 1st ed. NewDehli: Jaypee; 2013. p.175.

4. Dajani AS, Taubert KA, Gerber MA, Shulman ST, Ferrieri P, Freed M, et al. Special report: diagnosis and therapy of Kawasaki disease in children. Circulation. 1993;87:1776-80.

5. Hooker J, Mold J, Kumar S. Sterile pyuria in patients admitted to the hospital with infections outside of the urinary tract. J Am Board Fam Med. 2014;27:97-103. doi: 10.3122/jabfm.2014.01.130084.

6. Turner G, Coulthard C. Fever can cause pyuria in children. BMJ. 1995; 311:924.

7. Sharif M, Verdi J, Hosseinian M, Sharif A. Epidemiology of urinary tract infection at the pediatric section of Shahid Beheshti Hospital of Kashan. KAUMS J. 2001;4:83-8.

8. Oikonomou KG, Alhaddad A. The diagnostic value of urinalysis in hemodialysis patients with fever, sepsis or suspected urinary tract infection. J Clin Diagn Res. 2016;10:11-31.

9. Dieter R. Sterile Pyuria: A Differential Diagnosis. N Engl J Med. 2000;26:150-2.

10. Buys H, Pead L, Hallett R. Suprapubic aspiration under ultrasound guidance in children with fever of undiagnosed cause. BMJ. 1994;308:690-2.

11. Hiroko Shike, Kanegaye T, Brookie M, Pancheri J, Burns, I Pyuria associated with acute Kawasaki disease and fever from other causes. Pediatric Infect Dis J. 2009;28:440-3.

12. Choi J, Park S, Choi K, Park Y, Lee Y. Clinical Characteristics of Kawasaki disease with sterile Pyuria. Korean J Pediatr. 2013;56:13-8.

13. Jan SL, Wu MC, Lin MC, Fu YC, Vhan SC, Lin SJ, Pyuria is not always sterile in children with Kawasaki disease. Pediatr Int. 2010;52;113-7.

Copyright (C) 2019 The Author(s); Published by Nickan Research Institute. This is an open-access article distributed under the terms of the Creative Commons Attribution License (http://creativecommons.org/licenses/by/4.0), which permits unrestricted use, distribution, and reproduction in any medium, provided the original work is properly cited. 